Original Research Paper

\title{
Water Resource Evaluation and Identifying Groundwater Potential Zones in Arid area using Remote Sensing and Geographic Information System
}

\author{
${ }^{1, \S}$ M.M. Kamruzzaman, ${ }^{1}$ Saad Awadh Alanazi, ${ }^{1}$ Madallah Alruwaili, \\ ${ }^{1}$ Nasser Alshammari, ${ }^{1}$ Muhammad Hameed Siddiqi and ${ }^{2, *,}$ Md. Enamul Huq \\ ${ }^{I}$ College of Computer and Information Sciences, Jouf University, Sakaka, KSA \\ ${ }^{2}$ State Key Laboratory of Information Engineering in Surveying, \\ Mapping and Remote Sensing, Wuhan University, 129 Luoyu Road, Wuhan-430079, Hubei, China
}

\section{Article history}

Received: 25-12-2019

Revised: 24-02-2020

Accepted: 02-03-2020

Corresponding Author:

Md. Enamul Huq

State Key Laboratory of Information Engineering in

Surveying, Mapping and Remote Sensing, Wuhan University, 129 Luoyu Road, Wuhan-430079, Hubei, China Email: enamul_huq@whu.edu.cn

$\S$ Authors contributed equally for this work.

\begin{abstract}
Groundwater resource is the main conventional source of fresh water all over the world. However, recent revelations indicated that the shortage of water resources remains the main challenge for the arid areas. In this regard, identifying groundwater potential zones or areas can help to improve the availability of fresh water and effective management of groundwater in arid areas. This work finds the water resources and identify the groundwater potential zones of arid areas using remote sensing and GIS techniques. The study uses Kingdom of Saudi Arabia (KSA) as one of the most arid area and divides entire KSA into five regions namely northern, central, western, southern and eastern to evaluate and indicate the groundwater prospective zones effectively and clearly. The northern region (Al Jouf, Tabuk, Hail and Al-Qassim), Saq and overlying aquifers play an important role in water supply in Saudi Arabia. About $17.90 \%$ of the total area of this region identified as a groundwater potential zone. Based on geomorphological factors, the Wadi catchment areas act as the best appropriate regions for groundwater recharge in the northern area. Regarding the central region (Al-Riyad province), about $1.47 \%$ and $4.15 \%$ may be categorized as excellent and very good while $12.59 \%, 74.82 \%$ and $6.97 \%$ are considered as good, poor and very poor groundwater potential zone. In the western area (Wadi Yalanlan basin), the lower part of the Wadi Yalamlam basin is the most promising zone for groundwater availability containing both high and moderate potential areas. Also, high groundwater potential zones can be found on the northern side of the central dyke region surrounding Abu Helal's farm. 50.5\% and 31\% of the southern area (Jazan region) contain excellent and good groundwater potential areas while $16 \%$ and $2.5 \%$ of the regions showed average low groundwater potential zones. The eastern region had characteristics of extreme arid and desert environments. Based on the features, the area did not contain any groundwater potential zone. The current evaluation of groundwater potential areas in Saudi Arabia can serve as a significant tool for efficient groundwater resource management.
\end{abstract}

Keywords: Water Sources, Groundwater, Potential Zones, GIS, Remote Sensing, Saudi Arabia

\section{Introduction}

Water resources, including groundwater, play a vital role in providing fresh water for drinking, irrigation and industrial activities. However, increased extraction of groundwater from the various alluvial aquifers makes them susceptible to pollution-related activities (Huq et al., 2019; 2018a; 2018b; Su et al., 2016). This pollution hinders the water availability from the ground (Zaidi et al., 2015). Additionally, limited groundwater, occasional 
rainfall and high evaporation rates due to extremely high temperatures make the country one of the driest countries in the globe. Moreover, rapid industrial development and agricultural improvements play a crucial role in creating unmanageable groundwater abstraction and reducing water quality (Ahmed et al., 2015). Climate change also has created another challenge for water management in Saudi Arabia owing to scarce water sources. The utilization of groundwater acquired from aquifers located deep in the ground contributes to the depletion of water sources that have taken hundreds of years to amass. Furthermore, the present yearly precipitation in this area has no immediate impact to recharge the aquifers (Mahmoud and Alazba, 2016; Chen et al., 2019a). Because of the limited water sources and expansion of farming areas, it is thus important to delineate the groundwater potential regions. However, the use of Remote Sensing (RS) and Geographical Information System (GIS) remain the most advanced techniques utilized for the exploration of earth's resources, mapping and administration (Chen et al., 2020; 2019b). RS involves exploring groundwater utilization, monitoring and storage variations with the satellite data. Furthermore, GIS plays a vital role to obtain required data from various thematic maps and quick integration in order to identify the potential groundwater zones (Zaidi et al., 2015).

Several studies have done using RS and GIS technologies in hydrogeology field. Furthermore, various researchers have dealt with the identification of ground water zones using RS and GIS methods. Recently, researchers have successfully made efforts to demarcate possible groundwater areas using RS data. More recently, various investigations (Mahmoud and Alazba, 2016; Chen et al., 2019c; 2019d; 2019e; 2019f) revealed probable groundwater zones through the GIS and empirical techniques for groundwater recharge estimation. In general, in arid areas and specifically those in the western zone of Saudi Arabia, some investigations have completed on groundwater resources in the past few years. For example, A GIS approach was applied in Wadi Rabigh aquifer to assess the groundwater quality (Madani and Niyazi, 2015). Similarly, Mahmoud and Alazba (2016) discovered groundwater presence in aquifers of shallow dry areas using GIS method in Hada Al-Sham (El-Hames, 2005). The issue of groundwater potential demarcation using remote sensing and GIS evidence from Makkah Jurisdiction and Wadi Yalamlam catchment area in west KSA was carried out by Madani and Niyazi (2015). They found that the main aquifer in the region contained alluvial deposits. Another notable work Zaidi et al. (2015) introduced the hydrogeological susceptibility and pollution risk map for Al-Qassim, Al-Jouf and Tabuk aquifers using GIS techniques in northern Saudi Arabia. An et al. (2012), Coelho et al. (2017) and Nag and Saha
(2014) did excellent work in this area to assess the prospective artificial groundwater renewal areas. These studies utilized GIS and RS to determine the groundwater probable regions in the Bojnourd basin located in the north-west of Iran (Altafi Dadgar et al., 2017). In recent times, Al-Shabeeb et al. (2018), Altafi Dadgar et al. (2017) and Chen et al. (2019c; 2019d) utilized RS and GIS methods to demarcate groundwater potential areas in Azraq Basin in central Jordan and Leylia-Keynow watershed, southwest of Iran respectively. However, various studies performed indicated groundwater potential regions for the different zones in Saudi Arabia, but the intensive research work associated with the whole country does not exist.

Therefore, the present study attempts to mention the state of the water resources in Saudi Arabia and to identify the groundwater potential zones in the country by reviewing the existing studies. The contribution of this paper involves the assessment of related studies in Saudi Arabia and presents information about the areas that have high probability of having ground water. Indeed, the aim of the study revolves around discussions regarding water resources in KSA. Additionally, the main goal of this research is to review and present the utilization of RS and GIS techniques to discover groundwater potential zones in the different regions (northern, central, western and southern region) of KSA. The study might assist policy-makers and water resource planner to engage in appropriate expansion approaches and utilization of both surface runoff and groundwater sources.

\section{Methodology}

The subject associated with groundwater issues is profoundly interdisciplinary. As such, this assessment encompasses the consideration of the expansive assortment of reading resources, such as environmental sciences, geological science, GIS and remote sensing (Manap et al., 2014). The review involves the integration of technical and social standpoints. Accordingly, the definition of assessment and methods used in the study indicated the problems that the researcher identified to address. The search approaches were applied to access the right articles and related study materials from the various related sources, inclusion and exclusion criteria for pinpointing appropriate journals and documents, as well as review (Elbeih, 2015).

\section{Search Strategy and Scholarly Sources}

The searching process of related research work on groundwater potential zone was done extensively. Indeed, the search process aimed at identifying the relevant studies associated with groundwater, remote sensing and GIS. Equally, the utilization of standard 
search from electronic sources involved inquiring some significant academic materials extracted was done. A systematic search using keywords, such as 'water sources,' 'groundwater,' 'potential zones,' 'GIS,' 'remote sensing,' and 'Saudi Arabia' assisted in finding reliable sources. The keywords played an essential role in the search process for various categories of journals' key terms, abstract and title in order to exact some preliminary insights into the area of concentration due to the limitations linked to the overreliance on the keyword strategy. The particular articles were reviewed to classify the potential groundwater water zones in KSA.

\section{Inclusion and Exclusion Criteria}

The use of key questions from current and earlier studies from scientific investigations regarding groundwater was employed to choose the appropriate source of information. Initially, the selection was considered with the review purpose. The researcher focused on the documents that gave conclusive primary evidence from a systematic review of the assessment. Although specific procedural guiding principles were viewed significantly to ensure the significance of the assessment. The process followed the appropriate steps in order to permit flexibility in the use of the acceptable steps of analyzing the water resources, groundwater and application of RS and GIS in groundwater. The whole idea focused on the importance of collecting enough materials with relevant information. However, in order to ensure effective results, journals that failed to meet the set standards concerning aspects of applicability to the study were ignored. Indeed, each of the published articles assessed had the necessary information, including review of the objectives. Moreover, based on the abstract review, the assessment focused on the abstract contents to determine their relevance to review. The process ensured the consistent utilization of the inclusion and exclusion procedures, as well as re-reviews to solve the cases where it was difficult to reach to a conclusion. The procedure allowed the researcher to perfect and condense the scope of the study. The exclusion encompassed the use of specific conditions concerning the value of the research topic, including the process of identifying adequately searched and applicable information. The researchers attempted various approaches at the beginning of the literature review with an aim narrowing down to important documents about the topic and improve the understanding of the field.

\section{RS and GIS based Framework for groundwater potential zone mapping}

Remotely sensed indicators of groundwater may provide important data where classical alternatives are not available. Ground-based RS (geophysics) is usually more expensive than space and airborne RS but is still more accurate and cheaper than invasive methods (boring drilling). These indicators include vegetation surface water, water discharging to the surface carrying heat energy and runoff. Satellite technology is reviewed with respect to its ability to measure groundwater potential, storage and fluxes. Remotely sensed data are most useful where they are combined with GIS. GIS technology is able to provide an efficient handling and management of large and complex databases for groundwater assessment studies. The use of high-quality remotely sensed data, identification of pertinent hydrological, geological and geomorphological parameters, preparation of corresponding thematic maps, assigning appropriate weights and integration in a sophisticated GIS environment ensure and enhance the prediction accuracy of location of promising zones and their groundwater potential. The Fig. 1 shows RS and GIS based framework for groundwater potential zone mapping.

\section{Study Area}

\section{Location and Climate}

KSA is located in the arid region in the Middle East. It lies on the north of the equator and east of the Greenwich meridian (Fig. 2). Indeed, the total area of it is $2,149,690 \mathrm{~km}^{2}$ which makes it the globe's 13 th biggest country (Alharbi and Zaidi, 2018). Based on the sizes of the other countries in the Arabian Plate, it is geographically the biggest in the region. The Arabian Desert dominates the country's geography, which is associated with semi-desert, shrub land and numerous mountain ranges and highlands (AlSuhaimi et al., 2019). The country has a few lakes but does not have permanent rivers. However, apart from the Asir Province located in the southwestern region, KSA boasts of a desert climate associated with high temperatures during daytime and low temperatures in the night. In this case, normal summer temperatures reach about $45^{\circ} \mathrm{C}$ and up to a high of $54^{\circ} \mathrm{C}$ (Gubran et al., 2019). During the winter season, temperatures do not drop below the $0^{\circ} \mathrm{C}$ mark. In autumn and spring, the warmth remains moderate and temperatures recorded average $29^{\circ} \mathrm{C}$ (Al Zawad and Aksakal, 2010). Additionally, yearly rainfall is considerably low. The Asir zone has different climatic conditions associated with the influence of the Indian Ocean monsoon winds, which occur in October up to March. In this regard, an average rainfall of up to 300 $\mathrm{mm}$ takes place in this period, which constitutes approximately $60 \%$ of the yearly rainfall in KSA (Al-Omran et al., 2016). 


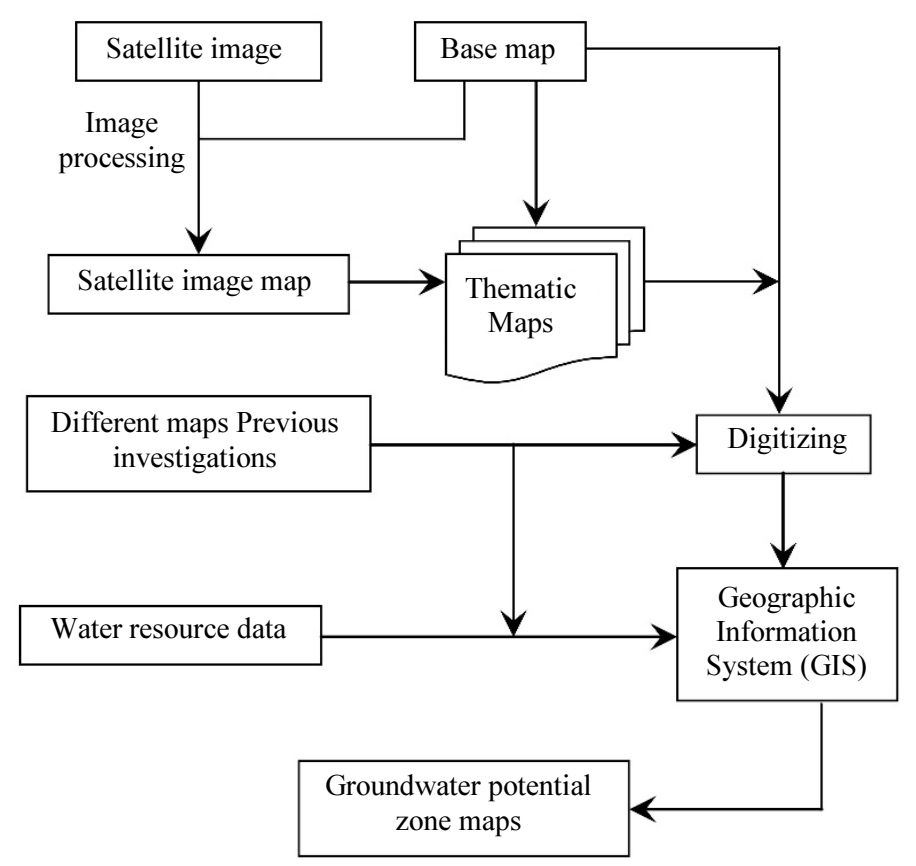

Fig. 1: RS and GIS based Framework for groundwater potential zone maps

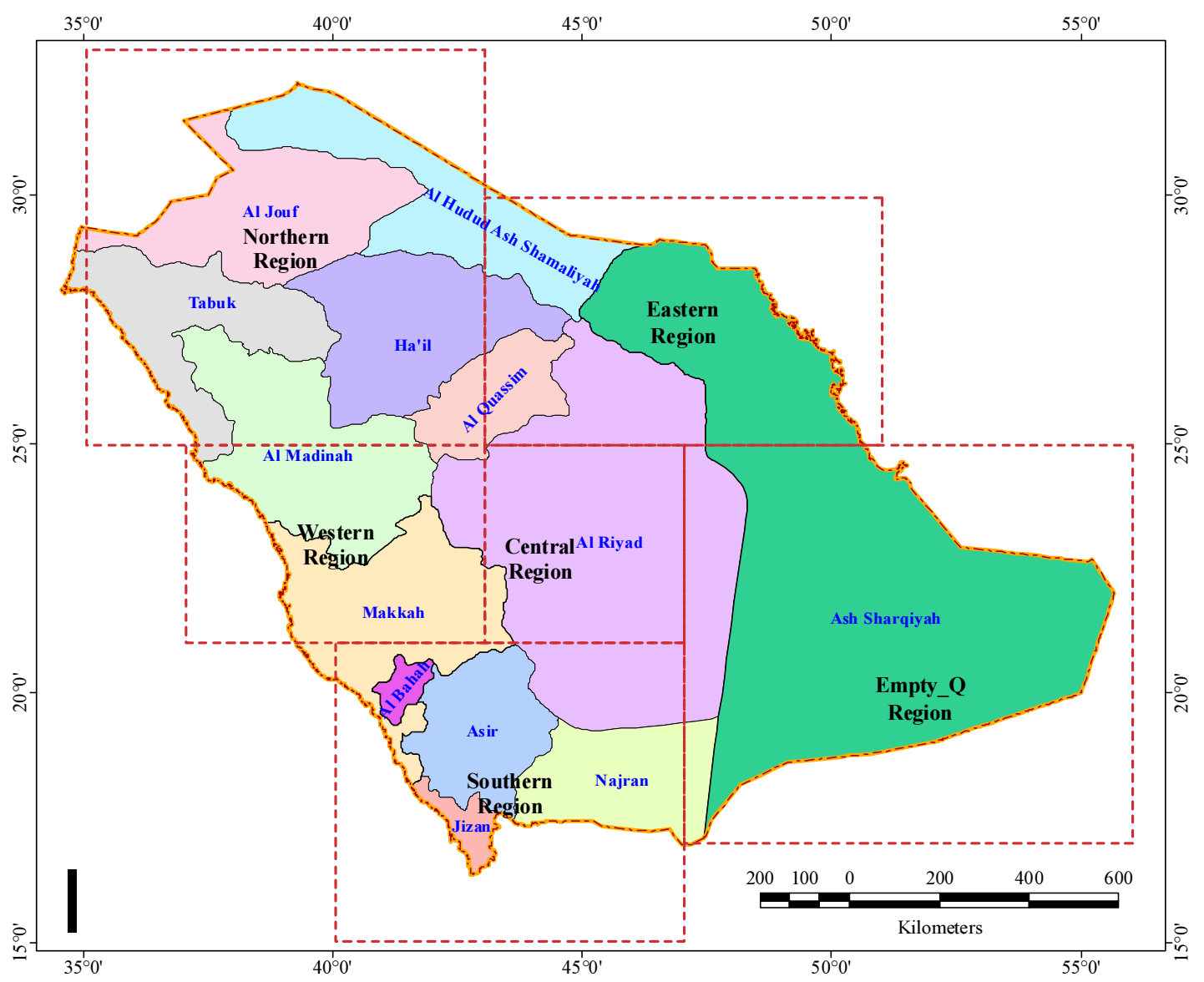

Fig. 2: Location of different regions in Saudi Arabia 


\section{Topography}

The central plateau represents the main topographical feature, which arises from the Red Sea's coastline and progressively slopes towards the Nejdin the direction of the Persian Gulf. Along the coast of the Red Sea, Tihamah parallel, athin coastal plain, runs a daunting escarpment. Besides, Asir Province has mountains, including Mount Sawda $(3133 \mathrm{~m})$, the highest one in KSA (DeNicola et al., 2015). On the side of the peninsula, people can see the Great Rift fault and escarpments that run along the Red Sea sandwiched between the Gulfs of Aqaba and Aden (Gabr et al., 2018; Madani et al., 2019). Regarding the escarpment, its eastern side slope remains comparatively placid and drops to the visible shield of the ancient land forming formed before the occurrence of the faulting process. A second and lower elevation, the Jabal Tuwayq, starts from northern side to the south via the Riyadh area. Subsequently, within the southern part, the Tihamah, a coastal plain landmass, rises progressively towards the mountains from the sea. Equally, Hejaz spreads towards the south to the borders of the mountainous of Yemen region. Najd, the centrally placed plateau, spreads east towards the Jabal Tuwayq region and Ad Dahna, an extensive longest of desert splits Najd from the eastern zones of KSA, which elevates towards the east to the Persian Gulf's sandy coastline (Alabdula'aly, 2014). In the northern part of Najd lies a specifically bigger desert, A Nafud, which separates the "heart of the peninsula" from the prairieland's region situated in northern part of Saudi Arabia (Fig. 3). The Rub al Khali in southern Najd remains as one of the biggest sand deserts in the universe.

\section{Geology and Hydrogeological Framework}

The Arabian Peninsula contains two major geologic units, including the eastern region that consists of progressively thickening Phanerozoic sedimentary. The western part that comprises of Pre Cambrian underground rocks regarded as the Arabian shield (An et al., 2012). The Saq Sandstone lies in the bottom of the alluvial sequence that emerges from a strip and uncomfortably overlying the basement. However, the superimposing formations appear one after another in sequential order and move far away from the interaction with the bottom ground in the eastern direction (Alsharhan et al., 2001). Also, the Cambro-Ordovician Saq formation that comprises majorly of moderate to uneven sandstones, which range in breadth from 400-928 meters, creates the main aquifer structure in KSA (Zaidi et al., 2015).

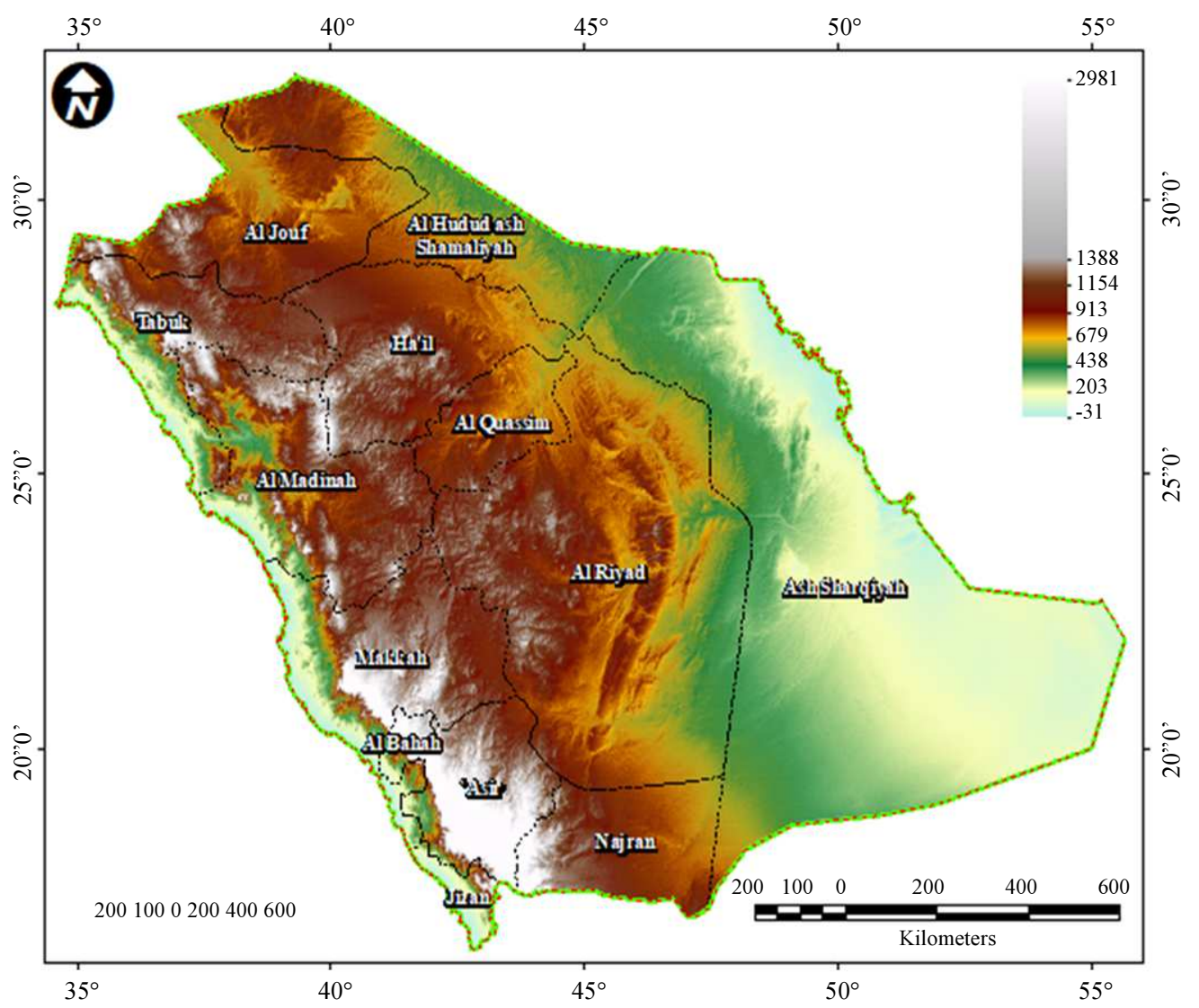

Fig. 3: Topographical map of Saudi Arabia 
This area represents multifaceted aquifer structure with the Saq formation which is the most well-known source of water resource. Based on the thickness, hydraulic features, water quality and the category of the aquifer other aquifer units become exposed. In this regard, individual farmers can meet their water needs for small-scale farming practices where they can drill wells that range from 100 to $150 \mathrm{~m}$ in depth in order to tap the various underground resources (Madani et al., 2019). Overall, there are eight principal (Neogene, Damman, UmmeErRadhuma, Riyadh and Wasia, Minjur and Daruma, Tabuk, Wajid and Saq) and nine secondary (Wadi sediments, Basalts, Aruma, Lower cretaceous, Sakaka, Upper Jurassic, Al-Jilh, Al-Khuf and Al-Jouf) aquifers or groups of aquifer are found in KSA (Zaidi et al., 2015).

Majority of the aquifers are explored in areas where they appear in conditions that are not confined.

\section{Water Resources in Saudi Arabia}

Before the 1980s, KSA had lakes located at Layla Aflaj and deep ponds situated at Al-Kharjand supplied by enormous subsurface aquifers formed during ancient times. In this case, Al-Kharj represented a treasured spring that supplied drinking water located in an unproductive area. In the recent past, the aquifers have been heavily drawn upon including domestic and agricultural purposes (Kim and van der Beek, 2018). Currently, no water remains in the lake sites or waterholes.

Without permanent sources of freshwater, including streams and groundwater, purified seawater and the scarce surface runoff water remain as the only sources of water in the country. Irrespective of the water challenges in KSA, the eastern region and Jabal Tuwayq have plenty of artesian wells and springs. Similarly, Al Ahsa has a large number of water pools that are regularly refilled by artesian springs due to the availability of groundwater that comes from the eastern water catchment area of the Jabal Tuwayq. Wells and springs supply the required water for irrigation activities in areas around the local oases (Alsamawi et al., 2018 Gandhidasan et al., 2018). The Hijaz is a region with many springs and wells that come from the hilly zones. Furthermore, in Najd and the great desert areas, water points are relatively fewer and dispersed in large areas. In this regard, the use of appropriate mechanisms such as pumping enables people to bring water to the surface but the water quality becomes poor. Saudi Arabia records approximately 158.47 billion $\mathrm{m}^{3}$ of rainfall water per annum. Moreover, it is estimated that the overall reserves situated in the sedimentary deposits around 84 billion $\mathrm{m}^{3}$ in one of the biggest sedimentary basin within Saudi Arabia (Alsamawi et al., 2018). Indeed, the total amount of extracted groundwater from groundwater sources in Saudi Arabia within the past 20 years is approximately
254.5 billion $\mathrm{m}^{3}$, which met the needs of the residents and utilization in irrigation (Tarawneh and Chowdhury, 2018). Irrespective of the amount of water withdrawn from the groundwater sources, the recharge of deep aquifers over the last two decades was confined to 41.04 billion $\mathrm{m}^{3}$. Furthermore, the non-renewable underground reserve is estimated to contain 259.1-760.6 billion $\mathrm{m}^{3}$ with an efficient yearly recharge of 886 million $\mathrm{m}^{3}$. Regarding the total internal renewable water, it stands at approximately 2.4 billion $\mathrm{m}^{3}$ per annum whereas 1.4 billion $\mathrm{m}^{3}$ of surface runoff is collected by 302 dams located in various regions of the country each year. The country contributes to the production of an estimated 1.06 billion $\mathrm{m}^{3}$ of desalinated water per annum. The treatment of waste water produces about 0.73 billion $\mathrm{m}^{3}$ annually (Alfaifi et al., 2018; Alkhudhiri et al., 2019).

However, the contemporary technologies have enabled people to identify the availability of underground water so that they can exploit it for domestic and industrial purposes. Saudi Aramco's (a Saudi Arabian Oil Firm) experts have discovered deep aquifers in various parts of northern and eastern KSA (Alsamawi et al., 2018). Moreover, the technicians established that the Wasilla, the biggest underground water point in KSA has more water as compared to the Persian Gulf. In this regard, the Saudi government, the United Nations (UN) and Saudi Aramco, as well as Food and Agricultural Organization (FAO) have established individual and combined efforts to explore groundwater resources (Madani and Niyazi, 2015; Gabr et al., 2018). Nevertheless, with this joint efforts, Saudi Arabia meets its citizens' water needs through the various water's sources, such as nonrenewable and renewable groundwater, desalinated water, renewable surface water and treated wastewater.

\section{Groundwater Potential Zones}

The current study classifies entire Saudi Arabia into six areas (northern, eastern, central, western, southern and, empty quarter region) to assess the underground water prospective zones (Fig. 2). The classification of the regions was done based on the geological, hydrological and meteorological features. In addition, the study identifies the eastern and empty quarter areas as extreme desert environments. As such, these two regions have no significant groundwater zones.

\section{Northern Region (Al Jouf, Tabuk, Hail and-Qassim)}

The northern region comprises three provinces (Al Jouf, Tabuk, Hail and Al-Qassim) of Saudi Arabia. In this zone, the Cambro-Ordovician Saq formation comprises course to medium sandstones that range from 400-928 $\mathrm{m}$ in thickness and creates the main aquifer structure in northern KSA (Zaidi et al., 2015). The region consists of six groundwater sources range from 
the lowest point to the top namely Saq and Kahfah granites (Qassim Formation); Quwarah (Qassim Formation) to Sarah granites (Tabuk Formation); Sharawra (Qalibah formation), as well as Tawil granites. The others include Jubah granite; Khuff limestone and Secondary (Mesozoic), which is tertiary to Quaternary (STQ) granite, as well as limestone rocks (El-Hames, 2005; Mahmoud and Alazba, 2014). The area also contains two layers (Al Jouf and granite and Unayzah and Berwath granites) that act provincially as aquitards but comprise units locally explored as underground water sources. Indeed, the Saq aquifer creates the most noteworthy water source although other groundwater sources play an essential role in increasing water supply in the country. In addition, the water table level ranges from $500-838 \mathrm{~m}$ above sea level. In this region, the groundwater flow comes from the south to north. The more groundwater exploitation is happened in Qassim region (Haider et al., 2017). Based on long-term research of the water cycle it is obvious that precipitation is the main source of recharging underground water. The water infiltrates through topsoil into the underground bedrocks and finally finds its path to the underground water catchment area.
Ahmed et al. (2015) did an excellent job in identifying the groundwater potential regions. In their work, thematic maps of various parameters, including vadose zone, soil texture, breadth, slope, the quality of underground water and type of water-bearing establishment were incorporated in GIS through the use of Boolean logic to categorize the groundwater potential areas in Northern Saudi Arabia. The land use/land cover map was employed to filter maps and to avoid the urban as well as agricultural area (Kim and van der Beek, 2018). After generating the various layers of separate parameters through the use of Boolean binary rationality (Zero representing inappropriate areas and on the appropriate regions), the use of appropriate operator helped to incorporate all thematic covers to produce the final possible groundwater areas. Finally, a proximity assessment was performed on the basis of the proximity of the ground water. About $17.90 \%$ of the entire area (Al Jouf, Tabuk, Hail and Al-Qassim) was found to be the potential groundwater recharge zone without the consideration of land utilization or land cover patterns (Haider et al., 2017). With the incorporation of land utilization, the possible groundwater recharge zone was identified as representing of $14.24 \%$ (Fig. 4).

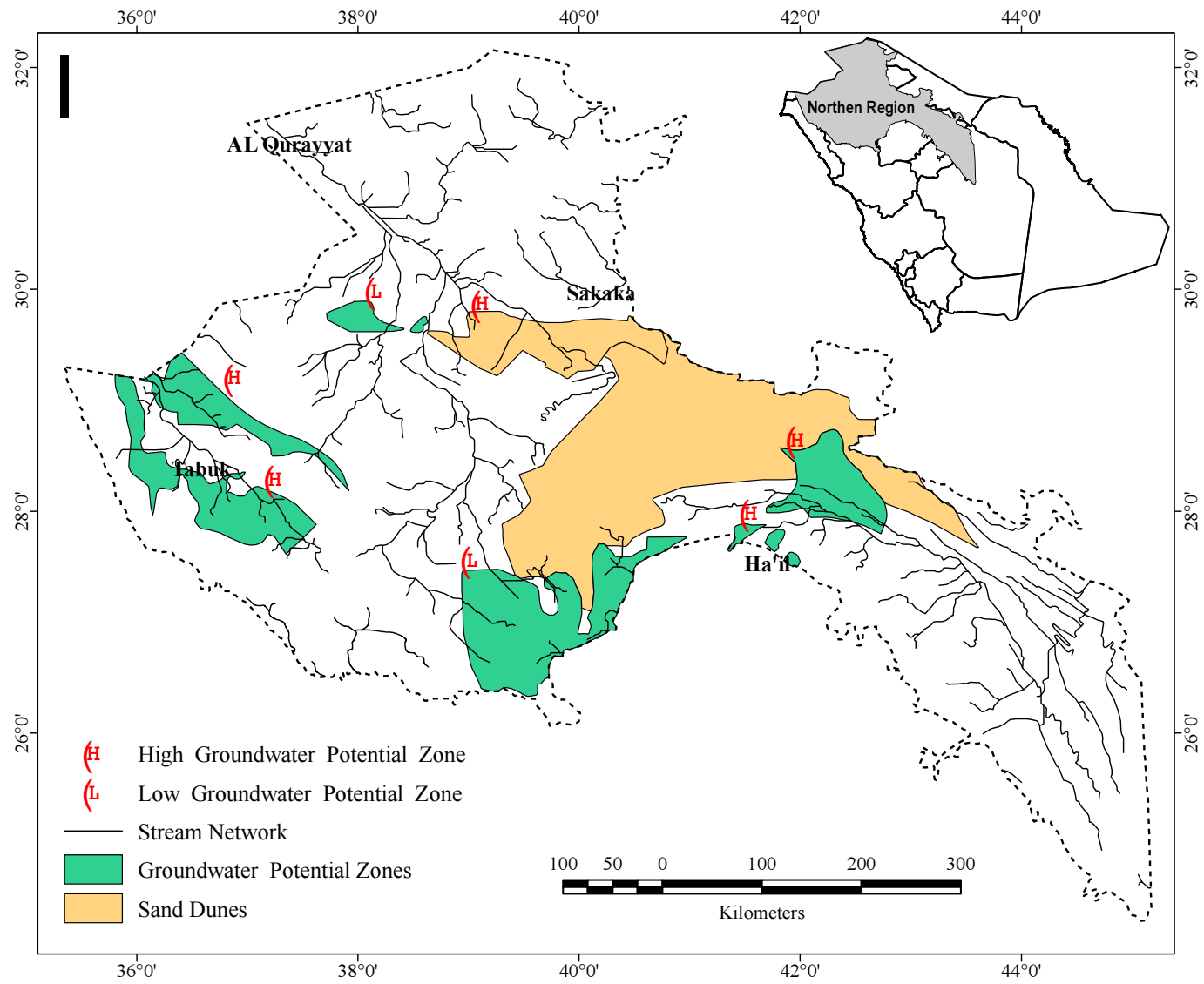

Fig. 4: Groundwater potential zone and artificial groundwater recharge zone northern region in Saudi Arabia (modified from (Zaidi et al., 2015)) 
While considering geomorphic elements, it became clear that Wadi catchments were the most appropriate for the groundwater zone whereas the sand dune areas had the lowest potential for groundwater. Certainly, because of low rainfall in the area, recharge of groundwater does not rely only on rains. Therefore, supplementary sources, including excess desalinated seawater and treated wastewater can act as potential sources of recharging underground water in this area.

\section{Central Region (Al-Riyadh Province)}

The Al-Riyadh Province (central region) represents the second biggest province in Saudi Arabia. In this zone, the highest (average) temperature appears at $42.6^{\circ} \mathrm{C}$ in July. However, winter seasons have warm days and relatively cold, as well as windy nights. Moreover, the average monthly humidity level ranges from $15 \%-51 \%$ during the summer and winter seasons, respectively (Alrehaili and Tahir Hussein, 2012). The mean yearly moisture levels reveal at $32.5 \%$. The general climate of this region is considered as arid and the metropolitan area receives yearly rainfall 41-230 $\mathrm{mm}$. For groundwater recharging and harvesting fiftyseven dams have been constructed in the area. Many areas of the central region have suitable slopes and extensively cultivated areas. Arenosols and Lithosols are the dominant soil types in this area. Based on structural analysis, the main lithological structures include carbonate stones, mixed alluvial consolidated rocks and alluvial deposits (Ahmed et al., 2015). The central region has carbonate-sulfate formations that spread to the Lower Cretaceous and the granite aquifers from the Lower Jurassic.

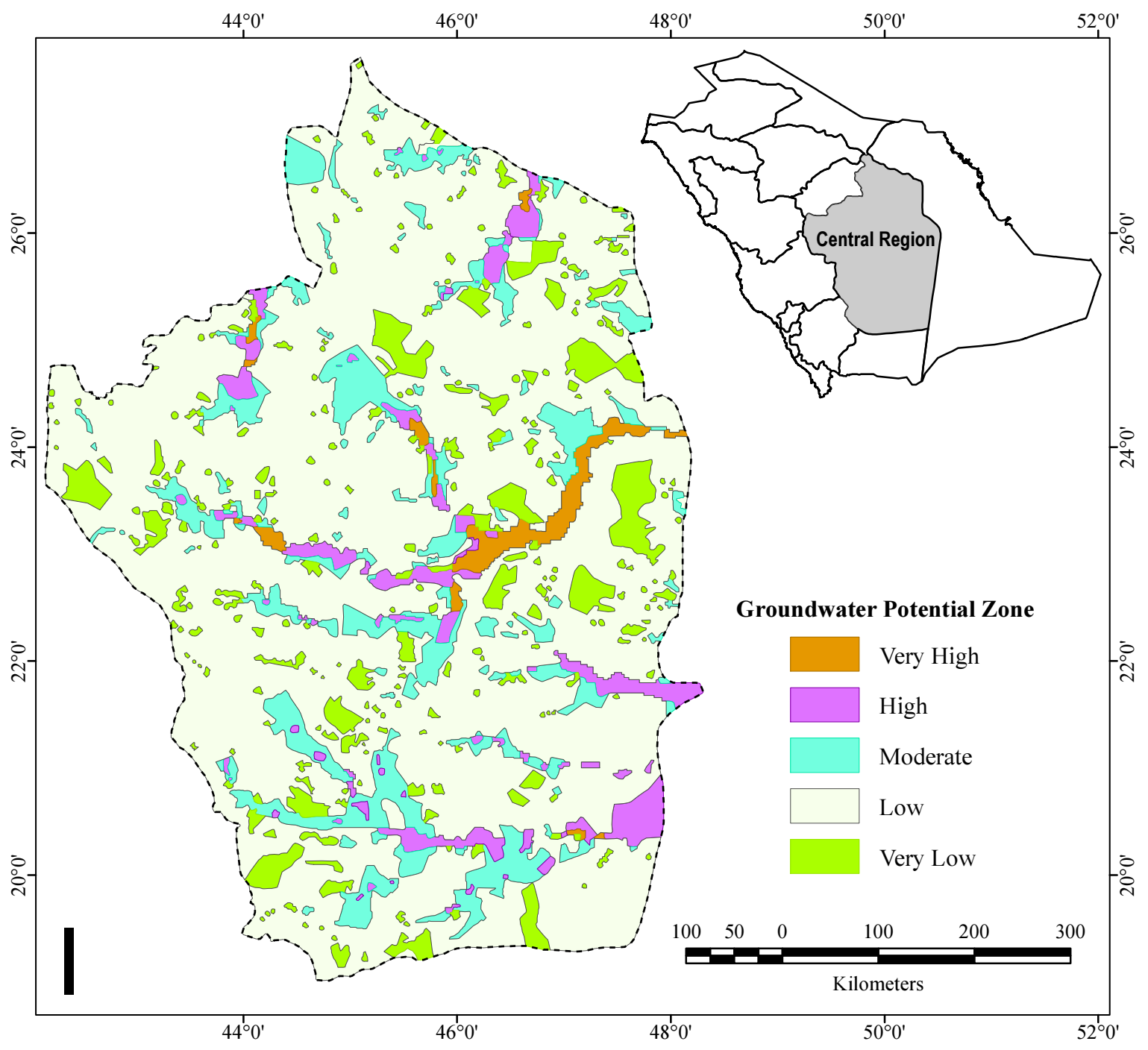

Fig. 5: Groundwater potential zone in central region in Saudi Arabia (adopted from (Mahmoud and Alazba, 2016)) 
A groundwater modeling analysis was done by Coelho et al. (2017) using GIS and remote sensing for identifying the groundwater probable areas in central region of Saudi Arabian. The study utilized RS and GISrelated decision provision structure to identify the groundwater potential areas in the central part of KSA. In this study, nine conditions were chosen for identifying and mapping groundwater potential zones. The features represent the nine thematic layers including, the type of soil, land cover utilization (derivative of the existing RS data), slope (landscape), lithology, precipitation, geological construction, geomorphology, lineament concentration and drainage compactness (Mahmoud and Alazba, 2016; Alharbi and Zaidi, 2018; Gubran et al., 2019). The various approaches were used and executed in generating groundwater potential area mapping, also an appropriateness model was created using the model builder of ArcGIS (Aydi, 2018). This suitability model creates an appropriate map for groundwater potential zones to generate different thematic maps such as the type of soil, land utilization and land cover, lithology, slope, precipitation, geological construction, geomorphology, lineament concentration and drainage compactness while utilizing the Weighted Overlay Process (WOP), as well as using both raster and vector databases. With the Analytical Hierarchical Process (AHP) analysis and considering the nine thematic aspects, the groundwater potential zones were categorized with the use of MultiCriteria Evaluation (MCE). Equally, the appropriateness model produced a groundwater potential zone map with five appropriateness classes (Chen et al., 2019c). The final result revealed that $1.47 \%$ and $4.15 \%$ area was categorized as excellent and very good correspondingly, while $12.59 \%, 74.82 \%$ and $6.97 \%$ areas classified as good, poor and very poor respectively (Fig. 5).

The spatial distribution of underground water prospective regions of the central zone indicated that 'excellent' groundwater potential areas were within Wadi channels located in the various areas of Al-Riyadh province (Gubran et al., 2019). It exhibits that water supply of Riyadh originates from the shallow underground water sources from the Wadi water channels. In addition, the karst aquifers linked with the carbonate-sulfate deposits, that extend to underground granite water sources and stretch towards the granite deposits of Minjur and Wasia formations from the Lower Jurassic to the Lower Cretaceous.

\section{Western Region (Wadibasin)}

Makkah Province is regarded as the western part of KSA. The water catchment area of this region is one of the biggest catchments in the KSA's western coast. This zone is extended towards the western coastline of Red Sea from the Arabian Shield, located in the eastern region. The climatic condition of this region is characterized by the arid features and has a desert environment, which remains hot and dry throughout the year. The average temperature arrays from $30^{\circ} \mathrm{C}-34^{\circ} \mathrm{C}$ in summer and $20^{\circ} \mathrm{C}-24^{\circ} \mathrm{C}$ during winter (Mahmoud and Alazba, 2016). Rainfall is unbalanced but increases towards the mountains as it comes from the coastal plains. Yearly average precipitation varies from 50 to $100 \mathrm{~mm}$. The humidity ranges between $30 \%-75 \%$. The evaporation rates vary from $200-500 \mathrm{~mm}$ per month. Wadi Rabigh's upper part of the catchment area is located Harrat Rahat plateau, which is associated with the flow of lava and Precambrian outcrops situated along the Hijaz escarpment (Gubran et al., 2019). In addition, the region's altitude begins at a few meters from the coastline and rises to $1,200 \mathrm{~m}$ at few inaccessible peaks towards the eastern side. The groundwater level can find close to the surface towards the edge of mountain encompassing the progression of the stream.

El-Hames et al. (2011) utilized GIS, statistical extrapolation and conditional overlaying methods, as well as observed two potential groundwater aquifers in two areas. The first one is situated in the lower region of Haqaq's spring towards the intersection with the bridge of Al Nuwabi. In this area, the depth of saturated area varies from 10-16 $\mathrm{m}$ and the other one is located in $\mathrm{Al}$ Nuwabi Wadi, an area where the thickness of the saturated area ranges between 20 and $35 \mathrm{~m}$ (El-Hames et al., 2011). El-Hames (2005) found that, zones with high groundwater potential are situated mostly in the alluvial part of the catchment, which form the Wadi Hishash in the middle-upper boundary and Wadi Madrakah at the higher boundary. In this region the wells, those contain groundwater accessibility were privately dug and are located in homesteads. The study also identified some alluvial areas in this region, which can produce an elevated pumping level based on the deep groundwater source. The condition is another evidence associated with the high groundwater possibility in this zone.

Madani and Niyazi (2005) performed a good job in outlining and mapping the groundwater probable areas at the Wadi Yalamlam (Sa'diyah sub-basin) using a unified approach with RS and GIS methods. The exploration used six thematic hydrogeological constraints and incorporated within the GIS environment. Based on this study, the lower areas of the Wadi Yalamlam basin provide encouraging indicators for groundwater potentiality since they comprise high and middle potential zones (Marko et al., 2014). The central and upper regions of the Wadi Yalamlam catchment symbolize low groundwater potential areas. Some parts, located in the middle of this area also exhibit as the high groundwater potential zone. In contrast, the lower part shows the moderate groundwater potentially (Fig. 6). Moreover, in this region, two dyking zones connects the various rock units in lower areas of the Wadi Yalamlam 
catchment. The first dyking zone can be observed from the west side of Sheikh Said's farm. This basic dyke strike approximately in the North-South direction. The other dyking area is seen in the southern side of Abu Helal's farm (Ahmed et al., 2015; Madani et al., 2019). The region possesses the Northwest Southeast direction. The presence of the dykes plays an important role for impacting the groundwater restoration in this zone by creating a subsurface water catchment area. The other dyking region creates a boundary between the moderate and high ground water probable zones. The high groundwater potential zones are situated in the northern side of main dyking zone and mostly covered by the loose Wadi deposits (Zaidi et al., 2015; Memon et al., 1986). Indeed, moderate slope, the deposits, flat zones, low drainage compactness and shallow groundwater areas create favorable situations for high groundwater probability, as well as high permeation levels that boost groundwater pools in the western region of Saudi Arabia. The moderate groundwater feasible zones are existing in the south of the key dyking area.

\section{Southern Region (Jazan region)}

Jazan region is situated in the southern part of KSA. This area represents the smallest area within Saudi Arabia as compared to the others. It consists of a desert climate accompanied by yearly temperatures of about $30^{\circ} \mathrm{C}$. The climatic conditions vary from exceptionally hot in the summer to a bit hot in short winter periods. Precipitation varies from 70-270 mm annually (Alfaifi et al., 2018). Since the region's economy is agricultural-based, the importance of availability of water and its effective management is imperative. In order to develop sufficient irrigation amenities, the responsible stakeholders need to focus on groundwater, which remains as the only possible source of water in this arid region. However, model builder tool associated with an ArcGIS model was used by Mahmoud and Alazba (2014) to detect the groundwater renewal potential zones in this region. The spatial extents of the appropriate probable groundwater recharge regions were recognized with the use of MCE based on AHP analysis (Saleem et al., 2019). For this analysis five layers were considered.

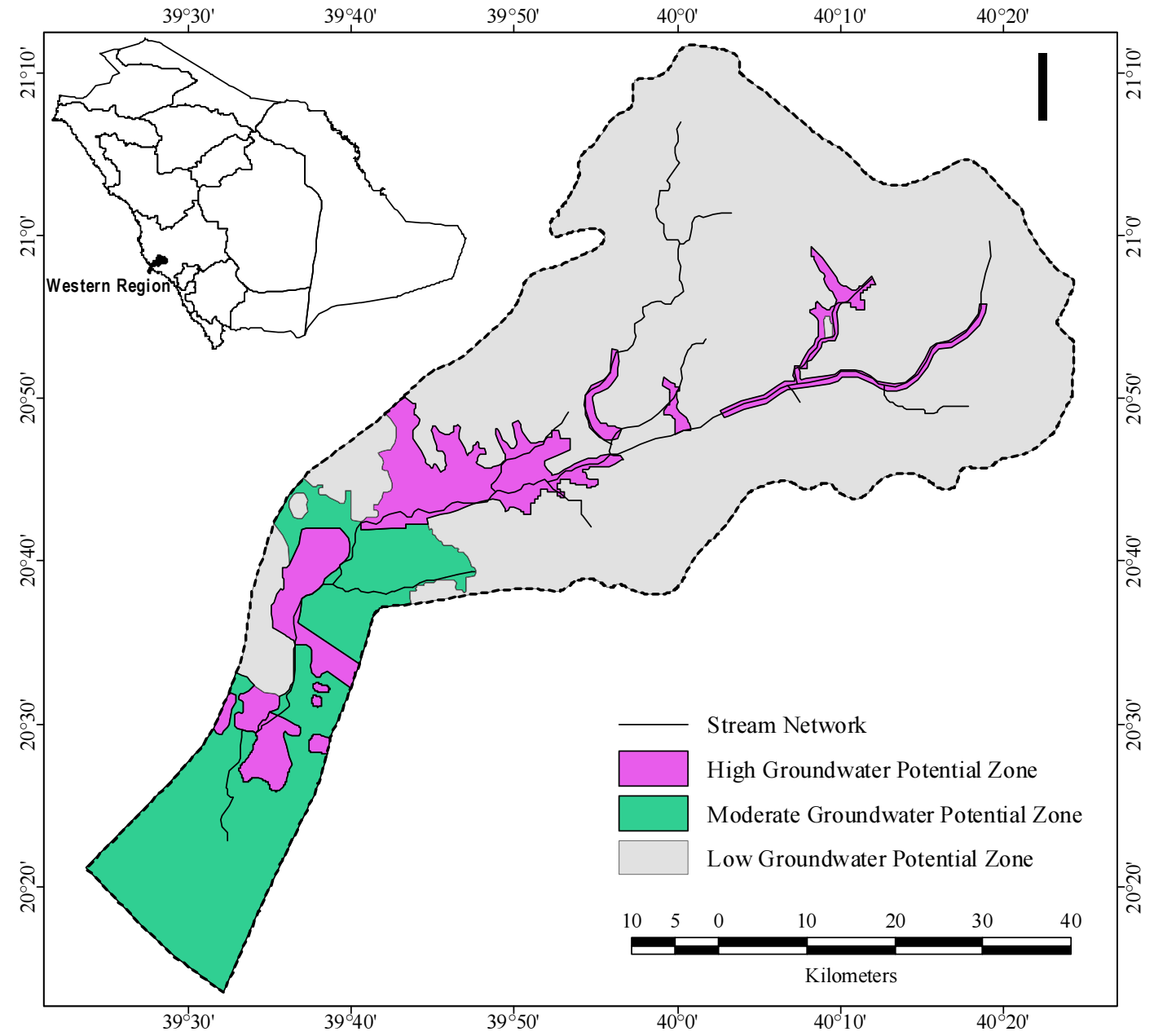

Fig. 6: Groundwater potential zone in western region in Saudi Arabia (modified from (Madani and Niyazi, 2015)) 


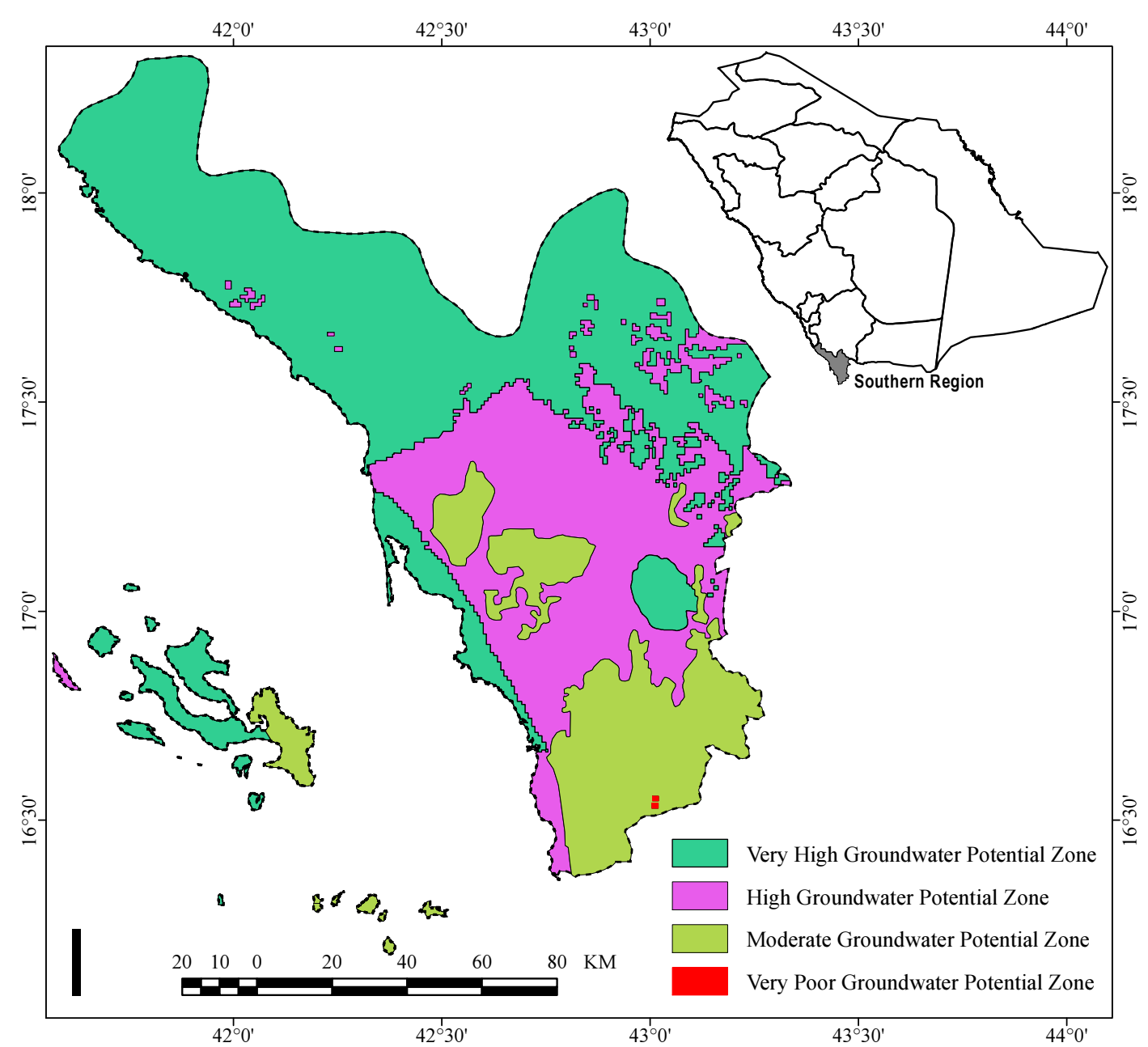

Fig. 7: Groundwater potential zone in western region in Saudi Arabia (adopted from (Mahmoud and Alazba, 2014))

Various spatial investigation was applied in the model to resolve the spatial challenges in the course of categorizing appropriate groundwater recharge zones. However, the spatial distribution of the groundwater recharge map indicates the excellent and good zones for potential groundwater recharge areas are situated within north and west of the Jazan region. While the middle area is also considered as excellent and good with some moderate zones. On the other hand, the southern and eastern areas have similar classifications with moderate suitable areas. Indeed, $50.5 \%$ and $31 \%$ of the area is categorized as having excellent and good potential groundwater recharge areas correspondingly. Whereas $16 \%$ is moderately suitable and $2.5 \%$ reflects poor and unsuitable zones (Fig. 7).

\section{Conclusion}

Saudi Arabia is naturally arid due to the limited rainfall; therefore, it faces scarce of surface water.
Hence, groundwater is regarded as the main water resource all over the country. In this paper, an integrated approach of RS and GIS was employed for evaluating the groundwater potential zones in Saudi Arabia. However, the study is important because it supports the sustainable use of groundwater resources and enhances the proper management of groundwater sources. However, the study revealed that in the northern region, the Wadi beds remain as the most appropriate for groundwater zone while the sand dunes had the least potential for groundwater. In central region ground water potential areas located in the Wadi channels within the southeastern parts of Al-Riyadh Province. Furthermore, in western region, the promising areas with groundwater potential in the aquifers are located in two places. The first one is situated in the lower part of Haqaq spring towards the intersection with Al Nuwabi. The other one is situated at Al Nuwabi Wadi. The high groundwater potential zones of western Saudi Arabia are situated mainly in the sedimentary area of the catchment of Wadi 
Hishash in the middle-upper boundary and Wadi Madrakah towards the upper boundary. In this area, some alluvial zones were found, which could produce a high pumping level owing to the deep groundwater point demonstrating the high groundwater potentiality in this region. In the southern region, the excellent and good potential groundwater zones are situated in the northern and western sides of the Jazan region. However, the application of RS and GIS techniques is quite effective to explore the ground water potential zones. The government and policymakers can use groundwater potential zone maps as an original reference in choosing appropriate locations for groundwater resources management effectively. The maps of groundwater potential zones would provide important information to the local resident and authorities, governments and developers regarding the appropriate region for groundwater extraction and protect the areas from pollution. Moreover, integrated RS and GIS based approaches act as a powerful tool for assessing potential groundwater areas. This review might play an important role in water resource management in the arid areas over the globe, since it may assist the stakeholders to take fast and effective decision.

\section{Funding}

This research was funded by Jouf University, grant number 40/168.

\section{Author's Contributions}

All authors (M.K., S.A., M.A., N.A., M.S. and M.H.) contributed in conceptualization, methodology, reviewing and editing. M.K., S.A and M.H. also contributed in designing and investigating the system. M.K. and M.H. implemented the system.

\section{Conflicts of Interest}

The authors declare no conflict of interest.

\section{References}

Ahmed, I., Y. Nazzal, F.K. Zaidi, N.S. Al-Arifi and H. Ghrefat et al., 2015. Hydrogeological vulnerability and pollution risk mapping of the Saq and overlying aquifers using the DRASTIC model and GIS techniques, NW Saudi Arabia. Environ. Earth Sci., 74: 1303-1318. DOI: 10.1007/s12665-015-4120-5

Al Zawad, F.M. and A. Aksakal, 2010. Impacts of Climate Change on Water Resources in Saudi Arabia. In: Global Warming, Dincer, I., A. Hepbasli, A. Midilli and T. Karakoc (Eds.), Springer, Boston, pp: 511-523.
Alabdula'aly, A.I., 2014. Occurrence of radon in groundwater of Saudi Arabia. J. Environ. Radioactivity, 138: 186-191.

DOI: 10.1016/j.jenvrad.2014.07.028

Alfaifi, H.J., K. Abdel Rahman, E.K.E. Ibrahim, A.Y. Kahal and F. Zaidi et al., 2018. Groundwater quality assessment in Southern Saudi Arabia Using Physico-Chemical water analysis. AGU Fall Meeting Abstracts.

Alharbi, T.G. and F.K. Zaidi, 2018. Hydrochemical classification and multivariate statistical analysis of groundwater from Wadi Sahba area in central Saudi Arabia. Arabian J. Geosci., 11: 643-643.

DOI: $10.1007 / \mathrm{s} 12517-018-3955-\mathrm{y}$

Alkhudhiri, A., N.B. Darwish and N. Hilal, 2019. Analytical and forecasting study for wastewater treatment and water resources in Saudi Arabia. J. Water Process Eng., 32: 100915-100915. DOI: 10.1016/j.jwpe.2019.100915

Al-Omran, A.M., A.A. Aly, M.I. Al-Wabel, A.S. Sallam and M.S. Al-Shayaa, 2016. Hydrochemical characterization of groundwater under agricultural land in arid environment: A case study of Al-Kharj, Saudi Arabia. Arabian J. Geosci., 9: 68-68. DOI: $10.1007 / \mathrm{s} 12517-015-2136-5$

Al-Shabeeb, A.A.R., R. Al-Adamat, A.K. Al-Fugara, A.H. Amoush and S. AlAyyash, 2018. Delineating groundwater potential zones within the Azraq Basin of Central Jordan using multicriteria GIS analysis. Groundwater Sustainable Dev., 7: 82-90.

DOI: $10.1016 /$ j.gsd.2018.03.011

Alrehaili, A.M. and M. Tahir Hussein, 2012. Use of remote sensing, GIS and groundwater monitoring to estimate artificial groundwater recharge in Riyadh, Saudi Arabia. Arabian J. Geosci., 5: 1367-1377. DOI: 10.1007/s12517-011-0306-7

Alsamawi, A., J. Murray, J. Gómez-Paredes and R.C. Reyes, 2018. Exporting water from the desert? An analysis of the virtual water content of Saudi Arabian agricultural exports. Int. J. Water Resources Dev., 34: 292-304.

DOI: $10.1080 / 07900627.2017 .1294051$

Alsharhan, A., Z. Rizk, A.E.M. Nairn, D. Bakhit and S. Alhajari, 2001. Hydrogeology of an Arid Region: The Arabian Gulf and Adjoining Areas. 1 st Edn., Elsevier, New York, ISBN-10: 0080534325, pp: 366.

AlSuhaimi, A.O., K.M. AlMohaimidi and K.A. Momani, 2019. Preliminary assessment for physicochemical quality parameters of groundwater in Oqdus Area, Saudi Arabia. J. Saudi Society Agric. Sci., 18: 22-31. DOI: $10.1016 /$ j.jssas.2016.12.002 
Altafi Dadgar, M., P. Zeaieanfirouzabadi, M. Dashti and R. Porhemmat, 2017. Extracting of prospective groundwater potential zones using remote sensing data, GIS and a probabilistic approach in Bojnourd basin, NE of Iran. Arabian J. Geosci., 10: 114-114. DOI: $10.1007 / \mathrm{s} 12517-017-2910-7$

An, Y., Y. Wang, H. Zhang and X. Wu, 2012. GIS-based suitability assessment for shallow groundwater development in Zhangye Basin. Proc. Environ. Sci., 12: 1397-1403. DOI: 10.1016/j.proenv.2012.01.442

Aydi, A., 2018. Evaluation of groundwater vulnerability to pollution using a GIS-based multi-criteria decision analysis. Groundwater Sustainable Dev., 7: 204-211. DOI: 10.1016/j.gsd.2018.06.003

Chen, G., Q. Pei and M.M. Kamruzzaman, 2020. Remote sensing image quality evaluation based on deep support value learning networks. Signal Processing: Image Commun. DOI: $10.1016 / \mathrm{j}$.image.2020.115783

Chen, G., X. Liu, Y. Wang, C. Tu and M.M. Kamruzzaman, 2019e. Measurement of environmental pollution sources by electron microscope remote sensing image algorithms. Acta Microscopica, 28: 1185-1194.

Chen, G., Z. Chen and M.M. Kamruzzaman, 2019d. Agricultural water efficiency evaluation method based on remote sensing technology. Revista de la Facultad de Agronomia de la Universidad del Zulia, 36: 1439-1450.

Chen, G., Z. Chen and M.M. Kamruzzaman, $2019 \mathrm{f}$. Monitoring of wildlife suitability habitat changes in nature reserves. Revista Científica, 29: 991-999.

Chen, G., Z. Jiang and M.M. Kamruzzaman, 2019b. Radar remote sensing image retrieval algorithm based on improved Sobel operator J. Visual Commun. Image Represent. DOI: $10.1016 /$ j.jvcir.2019.102720

Chen, G., Z. Sun and M.M. Kamruzzaman, 2019a. Application of microscope in the study of aquatic environment. Acta Microscopica, 28: 1176-1184.

Chen, G.B., X. Sui and M.M. Kamruzzaman, 2019c. Agricultural remote sensing image cultivated land extraction technology based on deep learning. Revista de la Facultad de Agronomia de la Universidad del Zulia, 36: 2199-2209.

Coelho, V.H.R., S. Montenegro, C.N. Almeida, B.B. Silva and L.M. Oliveira et al., 2017 Alluvial groundwater recharge estimation in semi-arid environment using remotely sensed data. J. Hydrol., 548: 1-15. DOI: 10.1016/j.jhydrol.2017.02.054

DeNicola, E., O.S. Aburizaiza, A. Siddique, H. Khwaja and D.O. Carpenter, 2015. Climate change and water scarcity: The case of Saudi Arabia. Annals Global Health, 81: 342-353.

DOI: $10.1016 / \mathrm{j} . \operatorname{aogh} .2015 .08 .005$
Elbeih, S.F., 2015. An overview of integrated remote sensing and GIS for groundwater mapping in Egypt. Ain Shams Eng. J., 6: 1-15. DOI: $10.1016 /$ j.asej.2014.08.008

El-Hames, A., 2005. Determination of groundwater availability in shallow arid region aquifers utilizing GIS technology: A case study in Hada Al-Sham, Western Saudi Arabia. Hydrogeol. J., 13: 640-648. DOI: $10.1007 / \mathrm{s} 10040-004-0323-7$

El-Hames, A., M. Al-Ahmadi and N. Al-Amri, 2011. A GIS approach for the assessment of groundwater quality in Wadi Rabigh aquifer, Saudi Arabia. Environ. Earth Sci., 63: 1319-1331. DOI: $10.1007 / \mathrm{s} 12665-010-0803-0$

Gabr, S.S., E.F. Farg, T.M. Habeebullah and S.M. Arafat, 2018. Irrigation water consumption and its impact on the groundwater aquifer of Wadi Uranah, Makkah, Saudi Arabia using remote sensing techniques. Egyptian J. Remote Sens. Space Sci. DOI: 10.1016/j.ejrs.2018.10.001

Gandhidasan, P., H.I. Abualhamayel and F. Patel, 2018. Simplified modeling and analysis of the fog water harvesting system in the Asir Region of the Kingdom of Saudi Arabia. Aerosol Air Quality Res., 18: 200-213.

DOI: 10.4209/aaqr.2016.11.0481

Gubran, M., H. Ghrefat, F. Zaidi and M. Shehata, 2019. Integration of hydrochemical, GIS and remotesensing data for assessment of shallow groundwater aquifers in Wadi Nisah, Central Saudi Arabia. Environ. Sci., 78: 161-161. DOI: $10.1007 / \mathrm{s} 12665-019-8164-9$

Haider, H., I.S. Al-Salamah and A.R. Ghumman, 2017. Development of groundwater quality index using fuzzy-based multicriteria analysis for Buraydah, Qassim, Saudi Arabia. Arabian J. Sci. Eng., 42: 4033-4051. DOI: 10.1007/s13369-017-2578-z

Huq, M.E., C. Su, J. Li and M.S. Sarven, 2018b. Arsenic enrichment and mobilization in the Holocene alluvial aquifers of Prayagpur of Southwestern Bangladesh. Int. Biodeteriorat. Biodegradat., 128: 186-194. DOI: 10.1016/j.ibiod.2018.01.008

Huq, M.E., C. Su, S. Fahad, J. Li and M.S. Sarven et al., 2018a. Distribution and hydrogeochemical behavior of arsenic enriched groundwater in the sedimentary aquifer comparison between Datong Basin (China) and Kushtia District (Bangladesh). Environ. Sci. Pollut. Res., 25: 15830-15843. DOI: $10.1007 / \mathrm{s} 11356-018-1756-1$

Huq, M.E., S. Fahad, Z. Shao, M.S. Sarven and A.A. Al-Huqail et al., 2019. High arsenic contamination and presence of other trace metals in drinking water of Kushtia district, Bangladesh. J. Environ. Manage., 242: 199-209. DOI: $10.1016 /$ j.jenvman.2019.04.086 
Kim, A. and H. van der Beek, 2018. A holistic assessment of the water-for-agriculture dilemma in the Kingdom of Saudi Arabia. Georgetown University in Qatar, Qatar.

Madani, A. and B. Niyazi, 2015. Groundwater potential mapping using remote sensing techniques and weights of evidence GIS model: A case study from Wadi Yalamlam basin, Makkah Province, Western Saudi Arabia. Environ. Earth Sci., 74: 5129-5142. DOI: 10.1016/j.jvcir.2019.102720

Madani, A., B. Niyazi, A. Elfakharani and H. Osman, 2019. The effects of structural elements on groundwater of wadi yalamlam, Saudi Arabia Using integration of remote sensing and airborne magnetic survey. Earth Syst. Environ., 3: 301-312.

DOI: $10.1007 / \mathrm{s} 41748-019-00091-3$

Mahmoud, S.H. and A. Alazba, 2014. Identification of potential sites for groundwater recharge using a GIS-based decision support system in Jazan regionSaudi Arabia. Water Resources Manage., 28: 3319-3340. DOI: 10.1007/s11269-014-0681-4

Mahmoud, S.H. and A. Alazba, 2016. Integrated remote sensing and GIS $\square$ based approach for deciphering groundwater potential zones in the central region of Saudi Arabia. Environ. Earth Sci., 75: 344-344. DOI: $10.1007 / \mathrm{s} 12665-015-5156-2$

Manap, M.A., H. Nampak, B. Pradhan, S. Lee and W.N.A. Sulaiman et al., 2014. Application of probabilistic-based frequency ratio model in groundwater potential mapping using remote sensing data and GIS. Arabian J. Geosci., 7: 711-724. DOI: $10.1007 / \mathrm{s} 12517-012-0795-\mathrm{Z}$

Marko, K., N.S. Al-Amri and A.M. Elfeki, 2014. Geostatistical analysis using GIS for mapping groundwater quality: Case study in the recharge area of Wadi Usfan, western Saudi Arabia. Arabian J. Geosci., 7: 5239-5252.

DOI: $10.1007 / \mathrm{s} 12517-013-1156-2$
Memon, B.A., A. Kazi, W.J. Powell and A. Bazuhair, 1986. Estimation of groundwater recharge in Wadi al-Yammaniyah, Saudi Arabia. Environ. Geol. Water Sci., 8: 153-153. DOI: 10.1007/BF02509903

Nag, S.K. and S. Saha, 2014. Integration of GIS and remote sensing in groundwater investigations: A case study in Gangajalghati Block, Bankura District, West Bengal, India. Arabian J. Sci. Eng., 39: 5543-5553. DOI: 10.1007/s13369-014-1098-3

Saleem, N., M.E. Huq, N.Y.D. Twumasi, A. Javed and S. Asif, 2019. Parameters derived from and/or used with Digital Elevation Models (DEMs) for landslide susceptibility mapping and landslide risk assessment: A review. ISPRS Int. J. Geo-Inform., 8: 545-569. DOI: 10.3390/ijgi8120545

Su, C., Y. Zhu, Z. Abbas and M.E. Huq, 2016. Sources and controls for elevated arsenic concentrations in groundwater of Datong Basin, Northern China. Environ. Earth Sci., 75: 570-570.

DOI: $10.1007 / \mathrm{s} 12665-016-5359-1$

Tarawneh, Q. and S. Chowdhury, 2018. Trends of climate change in Saudi Arabia: Implications on water resources. Climate, 6: 8-8. DOI: $10.3390 /$ cli6010008

Zaidi, F.K., Y. Nazzal, I. Ahmed, M. Naeem and M.K. Jafri, 2015. Identification of potential artificial groundwater recharge zones in Northwestern Saudi Arabia using GIS and Boolean logic. J. African Earth Sci., 111: 156-169.

DOI: $10.1016 /$ j.jafrearsci.2015.07.008 